\title{
Jogo Acidente Zero: elementos de gamificação para o ensino e aprendizagem de saúde e segurança do trabalho em um curso técnico integrado
}

Leandro Waltzer Einhardt, IFSUL, leandroeinhardt@,ifsul.edu.br

Carlos Emilio Padilla Severo, IFSUL, carlossevero@ifsul.edu.br

\begin{abstract}
RESUMO: este texto apresenta reflexões sobre gamificação na educação profissional, com base nos conceitos de educar pela pesquisa (DEMO, 2002), aprendizagem significativa crítica (MOREIRA, 2011), metodologias ativas (MORAN, 2017), engajamento escolar (SILVEIRA; JUSTI, 2018) e gamificação (FADEL et al., 2014). A metodologia foi de natureza qualitativa, cujos instrumentos de coleta de dados foram: entrevistas, questionários e observação participante. O jogo Acidente Zero foi elaborado e aplicado em uma prática educativa, onde os estudantes foram desafiados a resolverem problemas. Os resultados permitiram inferir que os elementos de gamificação escolhidos contribuíram para o engajamento comportamental, afetivo, cognitivo e agente dos estudantes.
\end{abstract}

Palavras-Chave: Gamificação, Jogo de tabuleiro, Ensino técnico integrado.

\section{Zero Accident game: gamification elements for Health and Safety at Work teaching and learning in a technical course}

\begin{abstract}
: this article presents reflections on gamification techniques in professional education. The concepts that supported this research were education through research (DEMO, 2002), critical meaningful learning (MOREIRA, 2011), active methodologies (MORAN, 2017), school engagement (SILVEIRA; JUSTI, 2018) and gamification (FADEL et al., 2014). The methodology chosen for the development of the research was of a qualitative nature, with data collection techniques based especially on conducting interviews, applying questionnaires and observing. The Board game Zero Accident was created and asks students to solve problems. The results of the evaluation of the activity allow to infer that the chosen gamification elements contributed to the behavioral engagement, affective, cognitive and agent of students.
\end{abstract}

Keywords: Gamification, Board game, Integrated technical education.

\section{Introdução}

A educação tradicional, na qual o professor ocupa o papel central em sala de aula e o aluno uma função passiva, agindo como receptor de informações, tem ocasionado, por vezes, desmotivação e desinteresse, visto que o estudante está acostumado a interagir com o conhecimento por meio de novas tecnologias da informação e comunicação (TICs).

Por isso, especialmente nas duas últimas décadas, o campo da educação tem desenvolvido pesquisas sobre diferentes experiências cognitivas, dentre elas, a gamificação, que "se constitui na utilização da mecânica dos games em cenários non 
games, criando espaços de aprendizagem mediados pelo desafio, pelo prazer e entretenimento" (ALVES et al., 2014, p.76).

Em decorrência da cultura digital, onde crianças e jovens do século XXI estão inseridos, a gamificação é comumente desenvolvida "a partir de imagens digitais ou eletronicamente produzidas e programadas para experiências pedagógicas, curriculares e interativas entre humanos e computadores" (FIGUEIREDO et al., 2015, p. 1154). Contudo, a gamificação também pode ser pensada fora do ambiente digital, pelo desenvolvimento de ferramentas que estimulem a interatividade e o prazer na aprendizagem, com o uso de elementos como missões e desafios, pontuações e ranqueamentos, prêmios e distinções, cenários, etc. Esses elementos podem ser usados para o tensionamento entre teoria e prática, estímulo à resolução de problemas e incentivo ao trabalho em grupo, que são práticas importantes durante o processo de desenvolvimento da aprendizagem.

Considerando a importância da gamificação na educação contemporânea, este artigo busca responder a questão problema: de que forma elementos de gamificação podem contribuir com o ensino e aprendizagem de Saúde e Segurança do Trabalho em curso técnico integrado ao ensino médio?

Sendo assim, o objetivo central do estudo foi compreender os processos de ensino e de aprendizagem com base em práticas pedagógicas gamificadas. Como objetivos específicos, apresentam-se: a) investigar os elementos de gamificação apropriados para ensino e aprendizagem; b) diagnosticar as preferências dos estudantes e a estrutura disponível para o desenvolvimento de elementos de gamificação; c) desenvolver elementos de gamificação para o ensino e aprendizagem; e d) analisar o uso de elementos de gamificação para o processo de ensino e aprendizagem de Saúde e Segurança do Trabalho.

O desenvolvimento destes objetivos resultou na elaboração, aplicação e avaliação do produto educacional jogo de tabuleiro Acidente Zero, criado em parceria com o Laboratório Experimental de Design do Instituto Federal Sul-rio-grandense, campus Pelotas. O desenvolvimento do jogo é apresentado nas próximas seções, que iniciam com a sistematização dos conceitos que embasaram sua elaboração.

\section{Fundamentação teórica}

Nesta seção, as principais referências teóricas que dão base à pesquisa sobre elementos de gamificação e sua aplicação para o ensino e aprendizagem são apresentadas. Inicia-se com reflexões sobre os princípios educacionais que regem a proposta: a educação pela pesquisa, vislumbrada por Demo (2002), aprendizagem significativa crítica de Moreira (2011) e metodologias ativas de Moran (2018). Na sequência, apresenta-se o fenômeno da gamificação a partir da obra de Fadel et al. (2014), abordando sua importância nos processos de ensino e aprendizagem.

$\mathrm{Na}$ consideração de que o ensino técnico integrado deve servir a uma proposta de sociedade menos exclusiva e desigual, fundada no trabalho como princípio educativo (FRIGOTTO, 2005), esta pesquisa foi apoiada no processo de formação da competência humana (DEMO, 2002, p.1). Para isso, duas principais concepções são importantes: sob o ponto de vista da educação, priorizar a ética da competência e, sob o ponto de vista da inovação, buscar o conhecimento crítico e criativo.

De acordo com o autor, o manejo da pesquisa como princípio educativo e atitude cotidiana são condições essenciais ao profissional da educação. Nessa ótica, conhecer é V. $18 \mathrm{~N}^{\mathrm{o}} 1$, julho, 2020 RENOTE DOI: 
a forma mais competente de intervir. A educação pela pesquisa proporciona o questionamento reconstrutivo a partir do conhecimento prévio. Assim, o questionamento reconstrutivo parte do senso comum do sujeito e permite que, com base na crítica, ele intervenha alternativamente, pelo conhecimento próprio renovado.

Ausubel (1963), conceituando a aprendizagem significativa, já citava o conhecimento prévio como a variável que mais influencia na aprendizagem - só se aprende a partir daquilo que já se conhece. Demo (2002) complementa, ponderando que a pesquisa não é processo exclusivo de espaços formais, como o ambiente escolar. A criança, ainda na primeira infância, conhece o mundo também pela pesquisa - quando pergunta sem parar, mexe nas coisas, desmonta e remonta brinquedos. O fato de os pais e a escola privilegiarem o excesso de disciplina, ordem e imitação, acaba atrapalhando esse comportamento pesquisador da criança.

Para que isso não aconteça, professor e aluno devem ser parceiros de trabalho, promovendo o educar pela pesquisa. $\mathrm{O}$ aluno deixa de ser objeto de ensino e se torna também protagonista no processo de pesquisa. Não é difícil pensar nesse processo sob o ponto de vista do aluno, principalmente quando se considera que a criança é pesquisadora nata e que os alunos de hoje compõem a geração de nativos digitais (MATTAR, 2009). Enquanto nativos digitais, os alunos se caracterizam como multitarefas, interativos, e aptos a trabalharem as informações mais rapidamente do que os professores conseguiriam transmitir. Por isso, o autor justifica a necessidade de aplicação do conhecimento por parte do aluno - o que pode ser pensado também sob a ótica do "educar pela pesquisa".

Para a operacionalização do educar pela pesquisa, percebem-se, em Demo (2002), alguns apontamentos importantes de reconfiguração do espaço escolar. Dentre eles, a proposta de que a configuração da sala de aula clássica seja repensada, para superação do contexto de treinamento e imitação; também, deve-se promover o trabalho em equipe, observando, claro, a evolução individual e a produtividade dos trabalhos; considera-se, ainda, que o estilo lúdico favoreça a motivação grupal. Esses apontamentos vão ao encontro do que Moreira (2011) trabalha como princípios para a aprendizagem significativa crítica, pensando em como fomentar a predisposição dos alunos a aprenderem, e à necessidade de pensar metodologias ativas, consideradas por Moran (2018) como "estratégias de ensino centradas na participação efetiva dos estudantes na construção do processo de aprendizagem, de forma flexível, interligada, híbrida".

O autor, ao abordar metodologias ativas, também observa que o aprendizado é favorecido através de práticas baseadas em atividades relevantes, as quais combinam a colaboração e personalização da aprendizagem. Tanto o educar pela pesquisa (DEMO, 2002) quanto os princípios para a aprendizagem significativa crítica (MOREIRA, 2011) ou a abordagem das metodologias ativas (MORAN, 2018) podem encontrar operacionalização no uso de elementos de gamificação para o ensino e aprendizagem.

Para Busarello et al. (2014, p.14), a gamificação tem como princípio "a apropriação de elementos dos jogos aplicados em contextos, produtos e serviços necessariamente não focados em jogos, mas com a intenção de promover a motivação e o comportamento do indivíduo". Não se trata exclusivamente de participar de um jogo, mas de usar mecânicas, estéticas ou dinâmicas para reproduzir os benefícios do ato de jogar. Dessa forma, a gamificação pode ser aplicada a atividades para as quais o objetivo é estimular um comportamento do indivíduo. 
Muito embora alguns elementos da gamificação já fizessem parte da área educacional há décadas, o interesse pela mecânica dos jogos tem se destacado em função da importância que os jogos assumiram sobre o comportamento do indivíduo na cultura digital (FADEL; ULBRICHT, 2014). Alves, Minho e Diniz (2014, p.82) explicam a utilização da gamificação em aplicativos que envolvem a inteligência coletiva e defendem que "pode-se também utilizar estratégias gamificadas para promover a motivação e o engajamento em diversos cenários de aprendizagem, sobretudo na escola”.

Em relação ao engajamento escolar, considera-se o conceito de Silveira e Justi (2018, p.110) para quem o "engajamento escolar refere-se ao nível de envolvimento do aluno em atividades escolares, envolvendo quatro aspectos: comportamental, cognitivo, afetivo e agente". Para os autores, engajamento comportamental se refere às atitudes positivas do estudante em relação ao cumprimento de regras e à adesão às normas da sala de aula; por sua vez, o engajamento cognitivo demonstra o nível de investimento e de valorização que o estudante apresenta em relação ao próprio aprendizado; o engajamento afetivo, também intitulado emocional, diz respeito aos sentimentos manifestados pelo aluno em sala de aula; já a dimensão de agência do engajamento se refere à contribuição construtiva, proativa e intencional do estudante para o fluxo da instrução que ele recebe. Acredita-se que a gamificação pode contribuir para a reação positiva do aluno nestes diferentes aspectos do engajamento.

Claro, para elaboração de estratégias em gamificação é preciso um esforço maior em relação a preparação de aulas tradicionais. Algumas sistematizações já foram desenvolvidas para auxiliarem os professores nessa jornada pela gamificação. Para Viana et al. (2013, apud BUSARELLO et al., 2014), existem quatro características essenciais na mecânica dos jogos, a constar: a meta do jogo, as regras, o sistema de feedback e a participação voluntária. Alves, Minho e Diniz (2014), por sua vez, sistematizaram as etapas de elaboração de estratégias de gamificação. Das onze etapas propostas pelos autores, as cinco primeiras podem ser caracterizadas como elaboração e planejamento dos elementos de gamificação. A partir da sexta etapa, foca-se mais precisamente no desenvolvimento dos elementos de gamificação, pensando na história que o jogo contará e suas relações com os conteúdos e competências esperadas, definição do ambiente, tipo de interação, tarefas, mecânica e o sistema de pontuação. Essa sistematização serviu de base para o desenvolvimento do jogo de tabuleiro Acidente Zero, produto educacional que será apresentado nesse artigo. Na próxima seção, são descritos os procedimentos adotados nas etapas de desenvolvimento, aplicação e avaliação do jogo.

\section{Métodos}

A pesquisa foi caracterizada como de natureza qualitativa, uma vez que envolveu a obtenção de dados descritivos, obtidos no contato direto do pesquisador com a situação estudada e se preocupou em retratar a perspectiva dos participantes (LÜDKE; ANDRÉ, 1986). Os procedimentos da pesquisa foram divididos em três principais etapas, cada uma com técnicas específicas de coleta de dados, são elas: 1) elaboração do produto educacional, a partir de entrevista com a docente responsável pela disciplina, aplicação de questionários aos discentes, respeito às etapas de desenvolvimento de elementos de gamificação propostas por Alves, Minho e Diniz (2014); 2) aplicação do produto educacional, com coleta de dados a partir de observação participante do 
pesquisador, realização de entrevista com a docente responsável e aplicação de questionários aos discentes; e, 3) avaliação do produto educacional.

O jogo Acidente Zero foi elaborado no período de 30 de setembro a 08 de dezembro de 2019. O nome do jogo foi inspirado em um canteiro de obras. A prática educativa com uso do jogo Acidente Zero ocorreu em duas horas/aula do dia 09 de dezembro de 2019, em sala de aula. O pesquisador leu as instruções do jogo e solicitou a divisão da turma em grupos de cinco pessoas. Enquanto os alunos jogavam, o pesquisador realizava a observação, de acordo com um roteiro planejado previamente. A prática do pesquisador, ali, assemelhou-se ao que Lüdke e André (1986) denominaram "participante como observador", uma vez que o pesquisador não ocultou totalmente suas atividades, mas revelou apenas parte do que seria observado, sem abordar que o comportamento, as falas, sentimentos e ações dos alunos também estavam sendo observadas.

Na semana subsequente à atividade do jogo, os estudantes responderam a um questionário semiestruturado para avaliação da prática. Este questionário também foi organizado conforme escala Likert. Tanto a observação realizada pelo pesquisador quanto o questionário respondido pelos alunos foram construídos considerando a ideia de engajamento escolar em seus quatro aspectos: comportamental, afetivo, cognitivo, e agente (SILVEIRA; JUSTI, 2018). No total, o questionário apresentou 20 questões, sendo cinco para cada aspecto do engajamento escolar.

Buscou-se verificar em que medida a narrativa desenvolvida conseguiu engajar os alunos, por meio de questões que pretendiam responder sobre o cumprimento às regras propostas pelo jogo (engajamento comportamental), sobre os sentimentos ocasionados com a prática (engajamento afetivo/emocional), acerca da valorização do conhecimento produzido no ato de jogar (engajamento cognitivo), e sobre a dimensão proativa e construtiva durante o jogo (engajamento agente).

Ainda para fins de avaliação da atividade, foi realizada uma entrevista presencial com a professora da disciplina na semana subsequente à prática. $\mathrm{O}$ jogo como produto educacional e os resultados de sua aplicação e avaliação são apresentados na seção seguinte.

\section{Análise e discussão dos resultados}

A partir da sistematização dos apontamentos decorrentes da entrevista com a professora, com vistas a definição do público, escopo, missão e objetivos dos elementos de gamificação, entendeu-se que: a) a principal competência a ser desenvolvida junto aos estudantes foi o conhecimento de normas básicas para monitoramento dos profissionais da área de segurança do trabalho; b) os elementos de gamificação deveriam explorar problemas relacionados à regulamentação das condições e meios de trabalho na indústria da construção; c) o principal objetivo a ser alcançado com a prática seria desenvolver o senso crítico e sensibilização dos estudantes em relação à importância da Segurança do Trabalho no seu fazer profissional; d) os elementos de gamificação deveriam ser analógicos, uma vez que nem todos os alunos têm acesso à tecnologias digitais em casa e o laboratório de Informática nem sempre estaria disponível para a disciplina.

A análise dos questionários respondidos pelos estudantes também resultou em dados importantes para a elaboração dos elementos de gamificação. Dos 19 respondentes do questionário, $63 \%$ consideram que aprendem mais em aulas práticas do 
que teóricas e que aprendem mais quando pesquisam sobre o tema, interagindo com o conhecimento. Além disso, $68 \%$ dos respondentes afirmou que aprende mais quando consegue relacionar o conteúdo com atividades do cotidiano e que prefere aula em canteiro de obras do que em sala de aula. Os alunos concordam, ainda, que aprendem mais quando são desafiados e $68 \%$ deles gostaria de ter aulas mais práticas/desafiantes. Dentre os respondentes, mais alunos preferem jogos de tabuleiro do que jogos de estratégia e apenas $15 \%$ teriam disponibilidade para realizar tarefas fora do horário escolar.

Definidos o público, escopo, missão e objetivos dos elementos de gamificação utilizados, as etapas de planejamento gráfico e narrativo do jogo foram realizadas. Então, o Acidente Zero foi construído baseado em desafios, os quais podem ser jogados individualmente, em duplas ou equipes. $\mathrm{O}$ jogo consiste em percorrer as 35 casas que compõem o tabuleiro, a partir de respostas corretas às cartas do jogo. Na medida em que os jogadores acertam a questão proposta, podem avançar a quantidade de casas apontada pelo jogo. O tabuleiro apresenta ilustrações de máquinas escavadeiras, caminhões, almoxarifado, banheiro, andaimes, tapumes, placas de identificação, materiais de construção, ferramentas, grua, trabalhadores, árvores e jardins, conforme Figura 1.

Das 35 casas que compõem o caminho a ser percorrido pelos jogadores, 27 são caracterizadas por cores e símbolos que representam as nove categorias de problemas propostos: quiz (verde), telefonema do escritório (amarela), identificando acidentes (vermelha), identificando sinalizações (cinza), no detalhe (lilás), atualização do mapa de risco (preta), flagra (laranja), curiosidade (marrom) e estagiário pergunta (azul). As demais oito casas (cinza) são situações que propõem o avanço ou o recuo de casas sem necessidade de respostas.

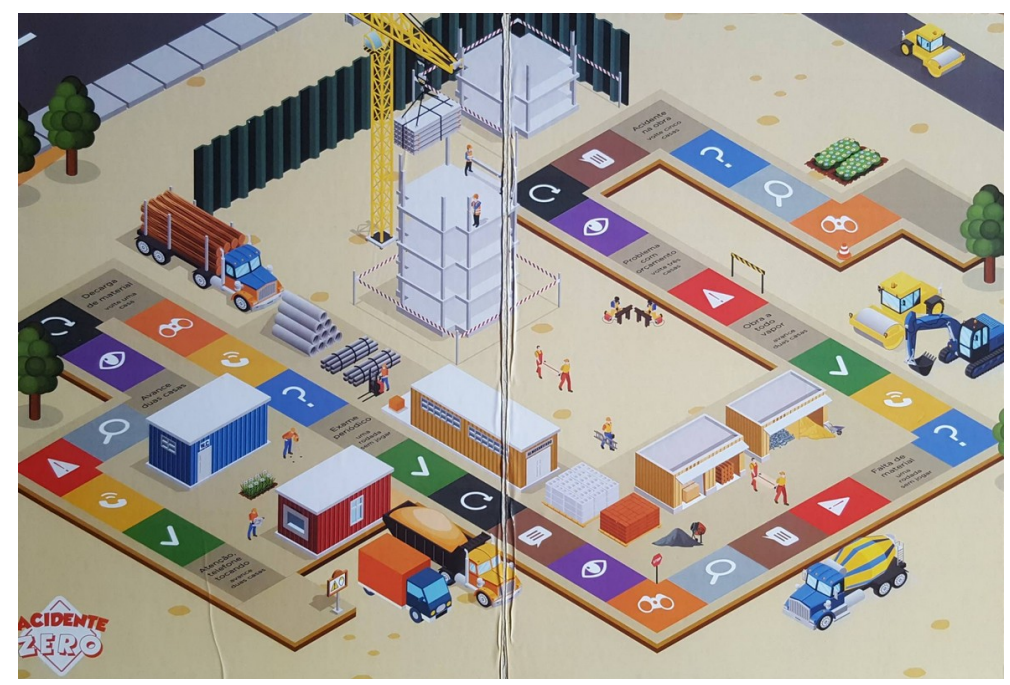

Figura 1. Fotografia do tabuleiro do jogo Acidente Zero. Fonte: dados da pesquisa, 2020.

As cartas foram divididas em nove categorias para contemplarem diferentes problemas e conhecimentos relacionadas a temática do jogo, são elas: 1) Questões mais simples, como o significado de siglas da área; 2) situações de acidente de trabalho, onde o jogador deve classificar e prevenir; 3) ilustra uma situação da obra e o jogador deve apontar o erro e solução; 4) sinaliza uma ordem da chefia para alguma ação e o jogador deve analisar se está correta; 5) apresenta questões para estagiários; 6) fotos de V. $18 \mathrm{~N}^{\mathrm{o}} 1$, julho, 2020 RENOTE DOI: 
equipamentos para identificação dos jogadores; 7) sinalizações importantes que devem ser identificadas pelos jogadores; 8) identificação de riscos em situações na obra; 9) curiosidades sobre o tema.

Cada categoria contém 20 cartas, totalizando 180 diferentes desafios no jogo. Esses desafios foram criados com base nos conteúdos trabalhados na disciplina. Para a aplicação na turma escolhida, foram impressas quatro unidades do jogo em gráfica particular e o orçamento total das impressões foi de $\mathrm{R} \$ 331,00$.

Considera-se que o jogo proporciona diferentes tensionamentos entre teoria e prática em Saúde e Segurança do Trabalho, buscando-se a sensibilização dos estudantes sobre a importância da adoção de medidas que evitem acidentes. A observação no decorrer da atividade permitiu inferir alto grau de engajamento comportamental dos estudantes. Eles ouviram as regras com atenção, jogaram obedecendo as regras, mesmo quando estavam perdendo, não demonstraram comportamentos inadequados durante a prática. Apenas um dos 18 alunos que participaram do jogo usou o celular sem fins didáticos durante a atividade e os colegas prontamente chamaram sua atenção para que voltasse ao jogo.

A percepção dos alunos sobre o engajamento comportamental corrobora com as observações do pesquisador. Nos questionários, 94\% dos alunos participantes concordaram que cumpriram as regras do jogo e que estiveram mais atentos no jogo do que em aulas expositivas e $88 \%$ deles sentiu-se fazendo parte da rotina de um canteiro de obras, demonstrando que o Acidente Zero cumpriu com o objetivo de simular situações práticas em Segurança do Trabalho.

Em relação ao comportamento afetivo, que "refere-se às reações afetivas do estudante em sala de aula" (SILVEIRA; JUSTI, 2018, p.111) e que demonstra também o vínculo dos alunos com a escola e com a comunidade escolar, a observação permitiu inferir que os estudantes interagiram muito bem na atividade, sendo cordiais, contribuindo com a construção das respostas, mesmo quando eram dadas por oponentes, e vibrando quando o colega avançava no caminho do tabuleiro.

A professora da disciplina também observou um comportamento mais interativo, dinâmico e proativo na atividade do jogo do que em aulas expositivas. Ela afirmou, em entrevista, que o jogo a fez concluir que "quando eles conseguem participar mais do processo de ensino, eles ficam mais engajados, atuantes, um lembrando o outro sobre o conteúdo, sobre as regras".

A análise dos questionários demonstra que os alunos também perceberam seu engajamento afetivo durante a prática do jogo. Cabe destacar que, embora tenham afirmado no questionário de diagnóstico a preferência por atividades individuais, $77 \%$ dos alunos afirmaram, depois do jogo, que escolheram sua dupla facilmente, $72 \%$ deles gostaram de jogar em duplas e $94 \%$ concordaram que foram cordiais com sua dupla durante o jogo. Em relação a essa interação entre colegas, a professora da disciplina, em entrevista, lembrou a fala de uma aluna durante o jogo: "uma aluna comentou que presta atenção nas aulas mas não sabe se está aprendendo e, com o jogo, eles puderam interagir entre eles e testar esse conhecimento".

Em relação aos sentimentos despertados pela atividade, 94\% dos alunos concordou que se sentiu empolgado durante o jogo e $77 \%$ deles sentiu-se mais feliz jogando do que participando de aulas expositivas.

O engajamento cognitivo "demonstra o nível de investimento e de valorização que o estudante apresenta em relação ao próprio aprendizado (...) e inclui flexibilidade em resolução de problemas, preferência por trabalhos difíceis e reações positivas diante 
insucessos" (SILVEIRA; JUSTI, 2018, p.111-112). Sobre o engajamento cognitivo, a observação durante o jogo demonstrou que os alunos consideraram o jogo difícil, mas se concentraram para resolver os desafios e buscaram avançar. Nos questionários, $27 \%$ dos alunos concordaram na consideração de que o jogo estava difícil e $27 \%$ discordaram desta sentença, sendo os demais indiferentes à questão da dificuldade. Ou seja, houve equilíbrio na consideração da dificuldade do jogo, mas $83 \%$ dos alunos afirmaram que errar durante o jogo serviu de estímulo para aprender mais, o que corrobora com o princípio da aprendizagem pelo erro observado por Moreira (2011).

A professora, em entrevista, não considerou o jogo difícil em relação aos conteúdos trabalhados em aula e ponderou que a forma como o jogo apresentou os problemas cotidianos do canteiro de obras poderia ser mais utilizada em sala de aula.

Além disso, 94\% dos alunos concordaram que aprenderam conteúdos novos com o jogo e 77\% deles afirmaram terem aprendido mais no jogo do que em aulas expositivas. Na questão aberta do questionário, em que poderiam colaborar com dicas sobre o jogo, apenas dois alunos se manifestaram, expondo: "Achei o jogo muito legal, não acho que tenha algo a melhorar. Parabéns! Aprendi muito" e "O jogo é ótimo, além de divertido, aprendemos com ele". Também durante o jogo, o pesquisador observou o comentário de uma aluna com seu grupo, afirmando que "Agora realmente aprendi Segurança do Trabalho".

Pondera-se, sobre as declarações dos alunos, que o sucesso do jogo dependia muito de conteúdos prévios já trabalhados por eles. Nesse sentido, recupera-se a ideia de aprendizagem significativa que, para Moreira (2011), acontece quando o aluno faz uso dos significados que já internalizou, de maneira substantiva e não arbitrária, para poder captar os significados dos materiais educativos. $\mathrm{O}$ acúmulo de conhecimento acerca de Saúde e Segurança do Trabalho, adquiridos em sala de aula ou no cotidiano fora da escola, foram importantes para que os alunos interagissem entre si a partir do jogo, aprendendo ainda mais um com o outro.

Por isso, recomenda-se o jogo como produto educacional que deve fazer parte de um plano de ensino, mas não como prática única desse plano. Moran (2018) fala da importância em combinar ambientes mais formais com os informais de maneira integrada, permitindo conciliar a necessária organização dos processos com a flexibilidade.

Por fim, sobre o engajamento agente, considerado como "a contribuição construtiva, proativa e intencional do estudante para o fluxo da instrução que ele recebe" (SILVEIRA; JUSTI, 2018, p.112), embora não apontado pela maioria dos alunos nos questionários, foi também observado durante o jogo.

Os alunos não colaboraram, nos questionários, com sugestões para a melhoria do jogo e afirmaram não terem percebido erros no produto. Contudo, durante a atividade, observaram algumas práticas que não estavam dando certo. Uma dupla, por exemplo, começou a usar o cronômetro do celular para controlar o tempo de respostas, uma vez que os colegas estavam demorando muito para responder. Nesse sentido, a professora da disciplina sugeriu, também, o uso de ampulhetas pra demarcação dos tempos de resposta de cada dupla no jogo. Outra observação dos alunos foi a incompatibilidade entre as respostas dos membros de uma dupla, ao que a professora recomendou que acordassem uma resposta final. Nesse sentido, ainda que não tenham contribuído formalmente para a melhoria do jogo, via questionário, os alunos engajaram-se em participar da atividade e, obedecendo suas regras, perceberam lacunas a serem 
corrigidas; $94 \%$ deles consideraram que participaram mais do jogo do que de outras aulas.

A professora da disciplina reconheceu o sucesso do jogo ainda no decorrer da atividade e, em entrevista, afirmou que "o material tem potencial para uma esfera interdisciplinar, para parceria em um trabalho integrador com outras disciplinas", o que abre a possibilidade de atuação do jogo Acidente Zero como produto educacional para outras instâncias além da situação em que foi aplicada. A professora da disciplina comunicou ao pesquisador, ainda, via e-mail, que a atividade foi citada por alunos na reunião avaliativa do semestre, conhecida por Conselho de Classe, como um exemplo de prática a ser adotada. E, ao finalizar a entrevista, a professora depôs: "eu tenho seis anos de docência e para mim foi uma das aulas mais prazerosas que vivenciei, porque quando tu vê o aluno buscando o conhecimento, interagindo com ele, não tem coisa melhor".

Dessa forma, entende-se que o jogo Acidente Zero funcionou como uma metodologia ativa, cumpriu seu objetivo em sensibilizar os alunos para a importância da área de Saúde e Segurança do Trabalho, engajou os alunos na obtenção de conhecimentos novos e proporcionou a interação com os colegas na produção desse conhecimento.

\section{Conclusão}

A pesquisa apresentada neste artigo considerou o fenômeno da gamificação como um campo de múltiplas possibilidades para a interatividade e o prazer na aprendizagem. Aliando essa compreensão à área de atuação do pesquisador, foi estipulado o objetivo central de compreender de que forma elementos de gamificação podem contribuir com o ensino e aprendizagem de Saúde e Segurança do Trabalho em curso técnico integrado. Esse objetivo foi cumprido a partir da observação de quatro principais etapas: averiguação dos elementos de gamificação mais efetivos para ensino e aprendizagem; diagnóstico das preferências em ensino dos alunos envolvidos; desenvolvimento do jogo de tabuleiro Acidente Zero, que simula um canteiro de obras e traz situações-problema em relação à Saúde e Segurança do Trabalho; e análise da efetividade do uso de elementos de gamificação a partir da aplicação e avaliação desse jogo em uma turma de ensino técnico integrado.

Os resultados da aplicação do jogo Acidente Zero, percebidos na observação da prática, bem como em entrevista realizada com a professora responsável pela disciplina e por meio de aplicação de questionários com os alunos envolvidos, permitiram observar que o jogo possibilita engajamento comportamental, afetivo, cognitivo e agente dos alunos. Estes cumpriram as regras estabelecidas, se sentiram motivados a resolverem os problemas propostos, interagiram com colegas em sua resolução, aprenderam conteúdos novos e revisaram temas já aprendidos.

Portanto, conclui-se que os elementos de gamificação podem contribuir com o processo de ensino e aprendizagem em Saúde e Segurança do Trabalho, uma vez que permitem a simulação de problemas práticos, a interação entre colegas, a abordagem de conteúdos já trabalhados ou conteúdos novos e a aprendizagem pelo erro, logo, aulas mais dinâmicas e lúdicas. Contudo, recomenda-se o uso de elementos de gamificação, como o jogo Acidente Zero, combinados às ferramentas mais formais de educação, que devem introduzir os conteúdos trabalhados, e não como abordagem única para o ensino e aprendizagem. 
Por fim, para pesquisas futuras, sugere-se que o jogo seja avaliado em diferentes situações do processo de ensino e aprendizagem - como revisão do conteúdo, avaliação, atividade interdisciplinar - buscando identificar as situações em que seu uso é mais efetivo para o engajamento escolar.

\section{Referências}

ALVES, L. R. G.; MINHO, M. R. S.; DINIZ, M. V. C. Gamificação: diálogos com a educação. IN: FADEL, L. M. et al. (orgs). Gamificação na educação. São Paulo: Pimenta Cultural, 2014. p.74-97.

AUSUBEL, D.P. The psychology of meaningful verbal learning. New York: Grune and Stratton, 1963.

BUSARELLO, R. I. et al. (orgs). A gamificação e a sistemática de jogo: conceitos sobre gamificação como recurso motivacional. IN: FADEL, L. M. et al. (orgs). Gamificação na educação. São Paulo: Pimenta Cultural, 2014. p.11-37.

DEMO, P. Educar pela pesquisa. Campinas/SP: Editora Autores Associados, 2002.

FADEL, L. M. et al. (orgs). Gamificação na educação. São Paulo: Pimenta Cultural, 2014. 300p.

FADEL, L. M.; ULBRICHT, V. R. Educação gamificada: valorizando os aspectos sociais. IN: FADEL, L. M. et al. (orgs).et al. (orgs). Gamificação na educação. São Paulo: Pimenta Cultural, 2014. p.06-10.

FIGUEIREDO, M.; PAZ, T.; JUNQUEIRA, E. Gamificação e educação: um estado da arte das pesquisas realizadas no Brasil. Anais... Workshops do IV Congresso Brasileiro de Informática na Educação. Maceió, AL, Outubro de 2015.

FRIGOTTO, G. Concepções e mudanças no mundo do trabalho e o ensino médio. In: FRIGOTTO, G.; CIAVATTA, M.; RAMOS, M. (orgs.). Ensino médio integrado concepção e contradições. São Paulo: Cortez, 2005. p.57-82.

LÜDKE, Menga; ANDRÉ, Marli E.D.A. Pesquisa em educação: abordagens qualitativas. São Paulo: EPU, 1986.

MATTAR, João. Games em educação: como os nativos digitais aprendem. São Paulo: Pearson, 2009.

MORAN, J. Metodologias ativas e modelos híbridos na educação. IN: YAEGASHI, Solange e outros (Orgs). Novas Tecnologias Digitais: Reflexões sobre mediação, aprendizagem e desenvolvimento. Curitiba: CRV, 2017, p.23-35.

MOREIRA, M. A. Teorias da Aprendizagem. São Paulo: EPU, 2011.

PINHEIRO, C. M. P. A história da utilização dos games como mídia. Anais. $4^{\circ}$ Encontro Nacional da Rede Alfredo de Carvalho, São Luís, 2006. Disponível em: http:// www.ufrgs.br/alcar/encontros-nacionais-1/encontros-nacionais/4o-encontro-2006-1.

Acesso em 13 de janeiro de 2019.

SILVEIRA, M. E.; JUSTI, F. R. dos R. Engajamento escolar: adaptação e evidências de validade da escala EAE-E4D. IN: Revista Psicologia: Teoria e Prática, 20(1), 110-125. São Paulo, SP, jan.-abr. 2018. 